\title{
Butyrate enema therapy stimulates mucosal repair in experimental colitis in the rat
}

\author{
J D Butzner, R Parmar, C J Bell, V Dalal
}

Abstract

Background-The short chain fatty acid (SCFA) butyrate provides energy for colonocytes, stimulates colonic fluid and electrolyte absorption and is recognised as an effective treatment for multiple types of colitis.

Aim-To examine the impact of butyrate enema therapy on the clinical course, severity of inflammation, and SCFA stimulated $\mathrm{Na}^{+}$absorption in a chronic experimental colitis.

Methods-Distal colitis was induced in rats with a trinitrobenzenesulphonic acid (TNBS) enema. Five days after induction, rats were divided into groups to receive: no treatment, saline enemas, or $100 \mathrm{mM}$ Na-butyrate enemas daily. On day 24, colonic damage score and tissue myeloperoxidase (MPO) activity were evaluated. Colon was mounted in Ussing chambers and $\mathrm{Na}^{+}$transport and elecbasal period and after stimulation with $25 \mathrm{mM}$ butyrate.

Results-In the untreated and the saline enema treated TNBS groups, diarrhoea and extensive colonic damage were seen, associated with increased tissue MPO activities and absent butyrate stimulated $\mathrm{Na}^{+}$absorption. In contrast, in the butyrate enema treated TNBS group, diarrhoea ceased, colonic damage score improved, and tissue MPO activity as well as butyrate stimulated $\mathrm{Na}^{+}$absorption recovered to control values.

Conclusion-Butyrate enema therapy stimulated colonic repair, as evidenced by clinical recovery, decreased inflammation, and restoration of SCFA stimulated electrolyte absorption.

(Gut 1996; 38: 568-573)

Keywords: short chain fatty acids, $\mathrm{Na}^{+}$absorption, diarrhoea, butyrate, colon transport.

Gastrointestinal Research Group, Faculty of Medicine, University of Calgary, Calgary, Alberta, Canada

J D Butzner

R Parmar

C J Bell

V Dalal

Correspondence to: Dr J Decker Butzner, Department of Pediatrics, 3330 Hospital Drive NW, University of Calgary, Calgary, Alberta, Canada T2N 4N1.

Accepted for publication 23 October 1995 bolism increases from the proximal to the distal colon. ${ }^{6}$ Butyrate also regulates epithelial proliferation and differentiation of the colonic mucosa. ${ }^{37-9}$ In addition, SCFAs trical activities were measured during a

stimulate sodium and fluid salvage by the colon. ${ }^{1-3}$

A growing body of evidence links deficiency, decreased absorption, and impaired metabolism of SCFAs to the pathophysiology of multiple types of diarrhoeal disease. Clinical findings suggest SCFA deficiency causes diversion colitis, an inflammatory reaction of the colorectum that occurs after surgical diversion of the colonic contents. ${ }^{10}$ Daily colonic perfusion with SCFAs stimulates both clinical and endoscopic remission of diversion colitis after only two weeks. Relapse can be prevented for prolonged periods with continued SCFA treatment. ${ }^{10}$ An acute infectious ileocolitis inhibits both SCFA stimulated electrolyte absorption and absorption of physiological concentrations of SCFAs in the rabbit. These transport abnormalities are associated with increased luminal concentrations of SCFAs. ${ }^{11}$ Ulcerative colitis inhibits both in vivo and in vitro SCFA oxidation by colonic epithelial cells. ${ }^{12-14}$ Furthermore, in the rat, metabolic inhibition of colonic epithelial SCFA oxidation causes colitis. ${ }^{15}$ Despite evidence for impaired SCFA oxidation in distal ulcerative colitis, enema therapy with combinations of SCFAs has been used successfully to treat this disease. ${ }^{1617}$ Furthermore, two clinical studies showed that enema therapy with $80-100 \mathrm{mM}$ butyrate as the sole SCFA, stimulated clinical, endoscopic, and histological improvement in patients with refractory distal ulcerative colitis. ${ }^{1819}$

Because of the success of butyrate enema therapy in distal ulcerative colitis, the aims of these experiments were: (a) to examine the effects of a chronic experimental colitis on in vitro SCFA stimulated electrolyte absorption; (b) to correlate changes in transport with other parameters of colonic damage and inflammation; and (c) to assess the effects of treatment with daily butyrate enemas given in a pharmacological concentration $(100 \mathrm{mM})$ on recovery of colonic structure and function. Experimental colitis was induced in rats with trinitrobenzenesulphonic acid (TNBS) and the resulting injury was examined for a short (five days) and a long (24 days) time period. TNBS colitis exhibits clinical, histological, and microscopic similarities to inflammatory bowel disease and the course of colonic injury has been well characterised. ${ }^{20-23}$

\section{Methods} colonocyte's dependence on SCFA meta-

\section{Animals}

Male Wistar rats (230-270 g) were purchased from Life and Environment Sciences Animal 
Resource Centre (Calgary, AB, Canada) and fed standard laboratory chow and tap water ad libitum. A constant photoperiod ( $14 \mathrm{~h}$ light, $10 \mathrm{~h}$ dark) and constant temperature of $20^{\circ} \mathrm{C}$ were maintained. Procedures for the care and handling of animals used in this study were approved by the University of Calgary Animal Care Committee and carried out in accordance with guidelines established by the Canadian Council on Animal Care. For 24 hours before the induction of colitis, rats were observed to ensure appropriate feeding behaviour and health. Weights as well as the presence and severity of diarrhoea were recorded daily.

\section{Induction of colitis}

Colonic inflammation was induced by a modification of the method described by Morris et al. ${ }^{20}$ On day zero, rats received $0.75 \mathrm{ml}$ of an enema containing $60 \mathrm{mg}$ of 2, 4, 6 TNBS (Fluka Chemical, Ronkonkoma, NY) dissolved in $30 \%$ ethanol (vol $/ \mathrm{vol})$, through a side hole catheter inserted into the colon with the tip $8-10 \mathrm{~cm}$ proximal to the anus. A control group received a single saline enema $(0.75 \mathrm{ml}$ of $0.9 \%$ saline) or no enema. Data on both sets of animals compromising this control group did not differ and are combined. Randomly selected animals from the TNBS colitis and control groups were evaluated on day five as outlined below. The remaining animals from both the TNBS colitis and control groups were randomly divided into three 'treatment' regimens. In the first treatment group, both controls and TNBS colitis animals received daily saline enemas $(140 \mathrm{mM} \mathrm{NaCl}, \mathrm{pH} 7 \cdot 0)$ for 19 days from day 5 to 23 . Controls and TNBS colitis animals in the second group received daily SCFA enemas (100 $\mathrm{mM} \mathrm{Na-}$ butyrate, $40 \mathrm{mM} \mathrm{NaCl}, \mathrm{pH} \mathrm{7.0}$ ) from day 5 to 23. The third group of controls and rats with TNBS colitis received no further treatment. This resulted in six treatment groups on day 24 of the study: saline enema - control, saline enema - TNBS colitis, butyrate enema - control, butyrate enema - TNBS colitis, untreated - control, and untreated - TNBS colitis.

\section{Assessment of damage and inflammation}

Rats were killed by cervical dislocation; the distal colon excised and luminal contents flushed with $\mathrm{HCO}_{3}{ }^{-}$-free HEPES buffer at $37^{\circ} \mathrm{C}$. The colon was opened by an incision along the mesenteric border and laid flat. An assessment of damage was scored on the segment of distal colon $5 \mathrm{~cm}$ in length proximal to the colorectal junction, using the criteria outlined in Table I adapted from J L Wallace et $a .^{21}$ This scoring system assesses the extent and severity of visible colonic damage; the presence and severity of adhesions; and as markers of diarrhoea, the presence of loose, watery stool or perianal fur soiling at the time of study. In the TNBS treated groups, injury was also seen 1-2 cm above this distal $5 \mathrm{~cm}$ segment. The $1 \mathrm{~cm}$ proximal end of this segment was excised, immediately frozen on dry ice, and stored at $-70^{\circ} \mathrm{C}$. Myeloperoxidase
TABLE I Criteria for scoring of colonic damage

\begin{tabular}{|c|c|}
\hline Feature & Score \\
\hline $\begin{array}{l}\text { Ulceration } \\
\text { Normal appearance } \\
\text { Focal hyperaemia, no ulcers } \\
\text { Ulceration without hyperaemia or bowel wall } \\
\text { thickening } \\
\text { Ulceration with inflammation at one site } \\
\geqslant \text { Two sites of ulceration and inflammation } \\
\text { Major sites of damage extending }>1 \mathrm{~cm} \text { along } \\
\text { the length of the colon } \\
\text { Damage extended to }>2 \mathrm{~cm} \text { along the length } \\
\text { of the colon, increase the score by one for } \\
\text { each additional cm of damage }\end{array}$ & $\begin{array}{l}0 \\
1 \\
2 \\
3 \\
4 \\
5 \\
6-10 \\
\text { plus }\end{array}$ \\
\hline $\begin{array}{l}\text { Adhesions } \\
\text { No adhesions to surrounding tissue(s) } \\
\text { Minor adhesions (colon can be separated from } \\
\text { other tissues with little effort) } \\
\text { Major adhesions } \\
\text { Diarrhoea } \\
\text { Absence of } \\
\text { Presence of }\end{array}$ & $\begin{array}{l}0 \\
1 \\
2 \\
0 \\
1\end{array}$ \\
\hline & $\overline{\text { Total score }}$ \\
\hline
\end{tabular}

(MPO) activity was determined as described by Morris et al and modified by Wallace et al within seven days of obtaining tissue. ${ }^{2021}$ MPO is an enzyme found in cells of myeloid origin, especially neutrophils. It provides a quantitative index of granulocyte infiltration in gastrointestinal tissues. ${ }^{24}$

\section{$\mathrm{Na}^{+}$transport and electrical activities}

For transport studies, a $4 \mathrm{~cm}$ section of the distal colonic segment was stripped of the serosa and underlying muscle layers with forceps. Adjacent pieces of the stripped colon were mounted in Ussing chambers with an exposed surface area of $0.4 \mathrm{~cm}^{2}$ and colonic transport as well as electrical activities were examined as previously described. ${ }^{11}$ Both the serosal and the mucosal sides of the tissue were bathed in $9 \mathrm{ml}$ of $\mathrm{HCO}_{3}{ }^{-}$free HEPES buffer at $\mathrm{pH} 6.8$ and $37^{\circ} \mathrm{C}$. These conditions maximise in vitro butyrate stimulated $\mathrm{Na}^{+}$absorption in rat distal colon. ${ }^{25}$ The buffer contained (in $\mathrm{mM}$ ): $120 \mathrm{Na}, 10 \mathrm{~K}, 1.1 \mathrm{Mg}, 1.25 \mathrm{Ca}$, $134.7 \mathrm{Cl}, 2 \mathrm{H}_{2} \mathrm{PO}_{4}, 25 \mathrm{HEPES}$, and 10 glucose. The solutions were maintained at $37^{\circ} \mathrm{C}$ with heated water jackets and circulated by a bubble gas lift mechanism containing $100 \% \mathrm{O}_{2}{ }^{11}$

The transepithelial potential difference (PD) was determined and the tissue clamped at zero voltage by continuously introducing the appropriate short circuit current $\left(\mathrm{I}_{\mathrm{sc}}\right)$ with an automatic voltage clamp (DVC 1000; World Precision Instruments, New Haven, CT). Every five minutes open circuit $P D$ was measured and tissue conductance (G) was calculated from PD and $\mathrm{I}_{\mathrm{sc}}$ according to Ohm's law.

When electrical parameters reached a steady state, $5 \mu \mathrm{Ci}$ of ${ }^{22} \mathrm{Na}$ (New England Nuclear, Montreal, QC, Canada) were added to either the mucosal or the serosal side of the paired chambers. After addition of isotope, reservoirs were allowed to equilibrate for 20 minutes. Steady state fluxes for the basal period were calculated from four samples obtained at time zero and five minute intervals for a total of 15 minutes. The samples were replaced with 
equal amounts of the $\mathrm{HCO}_{3}{ }^{-}$free HEPES buffer. Immediately after the basal period, $25 \mathrm{mM}$ Na-butyrate (final concentration) was added to the mucosal side while the serosal side received $25 \mathrm{mM}$ Na-isethionic acid to maintain osmolarity and volume. After a 10 minute equilibration period, a second set of flux measurements were performed over a 15 minute period as described above. The final concentrations of butyrate and isethionic acid in the bathing solutions remained constant throughout the experiment by replacement with buffer containing $25 \mathrm{mM} \mathrm{Na}$-butyrate or $\mathrm{Na}$-isethionic acid. If at any time during flux measurements the conductances of paired tissues differed by $>25 \%$, the experiment was rejected.

\section{Calculations and statistics}

Unidirectional mucosal to serosal $\left(\mathrm{J}_{\mathrm{ms}}\right)$ and serosal to mucosal $\left(\mathrm{J}_{\mathrm{sm}}\right)$ fluxes were calculated from aliquots at three consecutive five minute flux intervals and one overall 15 minute interval. The net flux $\left(J_{\text {net }}\right)$ for each period was calculated as the difference between oppositely directed unidirectional fluxes of tissue pairs. By subtracting $\mathrm{J}_{\text {net }}$ in the basal period from $\mathrm{J}_{\text {net }}$ in the stimulated period, the net effect of butyrate on sodium transport $\left(\Delta \mathrm{J}_{\text {net }}\right)$ was derived $\left[\Delta \mathrm{J}_{\text {net }}=\mathrm{J}_{\text {net }}\right.$ (stim) $-\mathrm{J}_{\text {net }}$ (basal) $]$. Data are expressed as means (SEM). A one way analysis of variance was used for multiple comparisons of data and unpaired $t$ tests used for comparisons within a group. $p$ Values of $\leqslant 0.05$ were considered significant.

\section{Results}

\section{Clinical}

On day zero, mean body weights did not differ between controls (241 (4) $\mathrm{g}, \mathrm{n}=32$ ) and the group to be treated with TNBS (253 (5), $\mathrm{n}=33$ ). All rats that received TNBS on day zero developed diarrhoea within 24 hours. By day five, when the first colonic studies were

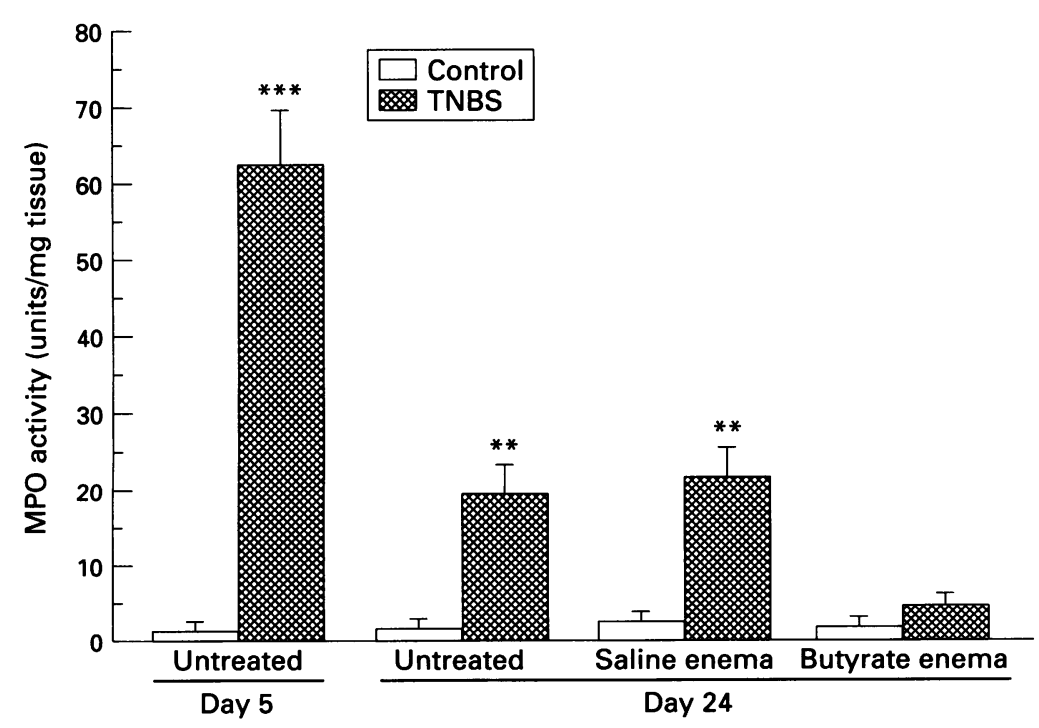

Figure 1: Tissue myeloperoxidase (MPO) activities in units/mg tissue for control and TNBS groups on day five or 24 for each treatment category. ${ }^{\star \star} p<0.01,{ }^{\star \star \star} p<0.001$ compares the TNBS colitis group with the respective control group. performed, all TNBS treated rats had persistent diarrhoea and developed significant $(\mathrm{p}<0.001)$ weight loss $(-7$ (2) g) compared with the weight gain (31 (5)) seen in controls. Diarrhoea persisted in most animals with TNBS colitis that received either no treatment ( 7 of 9 ) or 19 days of saline enemas (7 of 8 ). In contrast by day 24, diarrhoea ceased in seven of eight animals with TNBS colitis that were treated with butyrate enemas for 19 days. No diarrhoea was seen throughout the study period in controls that received no treatment or 19 days of either saline or butyrate enemas.

Weight gain from day 5 to 23 did not differ between the untreated (137 (11) $\mathrm{g}, \mathrm{n}=9$ ), saline enema treated $(120(8), n=7)$ or butyrate enema treated $(130(7), n=6)$ control groups. The weight gains of the untreated $(73$ (11) $\mathrm{g}, \mathrm{n}=9$ ) and saline enema treated (72 (10), $n=8$ ) groups with TNBS colitis were significantly decreased $(p<0.01)$ compared with their respective control groups. In contrast, the weight gain (98 (9) $\mathrm{g}, \mathrm{n}=8$ ) from day 5 to 23 of the butyrate enema treated TNBS group recovered to that of control groups.

\section{Colonic damage score}

In all groups of controls examined, either on day $5(n=10)$ or day $23(n=22)$, no colonic damage was seen and colonic damage score was zero. Colonic damage scores of rats with TNBS colitis, including the untreated group examined on day five $(10 \cdot 0(0 \cdot 7), \mathrm{n}=8)$ as well as the untreated $(8.0(0.8))$ and saline enema treated $(7 \cdot 8(0 \cdot 6))$ groups examined on day 24 , were significantly higher $(p<0.01)$ compared with the butyrate enema treated TNBS group examined on day $24(3 \cdot 7(0 \cdot 6))$. Two animals in the butyrate enema treated TNBS group displayed focal hyperaemia of the colon and in six rats, one small area of ulceration was seen, associated with a minor adhesion in three. Severity of colonic damage did not differ between the untreated TNBS colitis group examined on day five and either the untreated or the saline enema treated TNBS colitis groups evaluated on day 24 of the study. Ulcers in these three groups were increased both in number and size compared with the butyrate enema treated TNBS group. Also, both minor and major adhesions were seen.

\section{Tissue MPO activity}

Tissue MPO activities of the respective control groups were all less than 3 units/mg tissue and did not differ between treatment groups (Fig 1). On day five of the study, colonic MPO activity was significantly increased $(p<0.001)$ in the TNBS group compared with untreated controls (Fig 1). On day 24 of the study, colonic MPO activities in the untreated and the saline enema treated TNBS groups were significantly decreased $(\mathrm{p}<0.01)$ compared with the TNBS group on day five, but remained significantly increased $(p<0.01)$ compared with values of their respective control groups on day 24 (Fig 1). In contrast with the persistent increases in tissue MPO 
TABLE II $\mathrm{Na}^{+}$Transport and electrical activities in rat distal colon

\begin{tabular}{|c|c|c|c|c|c|c|}
\hline Study period & Number & $\boldsymbol{f}_{\mathrm{ms}}$ & $\boldsymbol{f}_{\mathrm{sm}}$ & $\mathfrak{f}_{\text {net }}$ & $I_{\mathrm{sc}}$ & $G$ \\
\hline \multicolumn{7}{|l|}{ Day 5} \\
\hline $\begin{array}{l}\text { Basal } \\
\text { Butyrate } \\
\text { p Value }\end{array}$ & 10 & $\begin{array}{c}11.4(0.8) \\
15.9(0.9) \\
<0.01\end{array}$ & $\begin{array}{c}5.1(0.5) \\
5.3(0.5) \\
\text { NS }\end{array}$ & $\begin{array}{c}6.3(0.9) \\
10.5(0.9) \\
<0.01\end{array}$ & $\begin{array}{c}1.0(0 \cdot 2) \\
0.6(0 \cdot 1) \\
\text { NS }\end{array}$ & $\begin{array}{c}10(1) \\
11(1) \\
\text { NS }\end{array}$ \\
\hline $\begin{array}{l}\text { Untreated - } \\
\text { Basal } \\
\text { Butyrate } \\
\text { p Value }\end{array}$ & $\begin{array}{c}\text { NBS } \\
8\end{array}$ & $\begin{array}{c}13.4(0.8) \\
11.6(0.6) \\
\text { NS }\end{array}$ & $\begin{array}{c}11.9(0.9) \\
12.0(1.0) \\
\mathrm{NS}\end{array}$ & $\begin{array}{c}1.5(0.8) \\
-0.4(1.0) \\
\text { NS }\end{array}$ & $\begin{array}{c}0.6(0.3) \\
0.7(0.2) \\
\text { NS }\end{array}$ & $\begin{array}{c}52(6) \\
38(4) \\
\text { NS }\end{array}$ \\
\hline \multicolumn{7}{|l|}{$\begin{array}{c}\text { Day } 24 \\
\text { Untre }\end{array}$} \\
\hline $\begin{array}{l}\text { Basal } \\
\text { Butyrate } \\
\text { p Value }\end{array}$ & 9 & $\begin{array}{c}11.8(0.8) \\
15.9(0.7) \\
<0.01\end{array}$ & $\begin{array}{l}5 \cdot 6(0.4) \\
5.9(0.4) \\
\text { NS }\end{array}$ & $\begin{array}{c}6.1(0.9) \\
10.0(1.0) \\
<0.01\end{array}$ & $\begin{array}{c}0.9(0.1) \\
0.9(0.2) \\
\text { NS }\end{array}$ & $\begin{array}{c}13(1) \\
14(1) \\
\text { NS }\end{array}$ \\
\hline \multicolumn{7}{|c|}{ Untreated - TNBS } \\
\hline $\begin{array}{l}\text { Basal } \\
\text { Butyrate } \\
\text { p Value }\end{array}$ & 8 & $\begin{array}{c}12.9(1.9) \\
14.3(1.6) \\
\text { NS }\end{array}$ & $\begin{array}{c}7.9(1 \cdot 1) \\
10.4(0.9) \\
\text { NS }\end{array}$ & $\begin{array}{c}4.9(0.9) \\
3.8(1 \cdot 2) \\
\text { NS }\end{array}$ & $\begin{array}{c}0.7(0.4) \\
0.4(0.2) \\
\text { NS }\end{array}$ & $\begin{array}{c}23(3) \\
30(4) \\
\mathrm{NS}\end{array}$ \\
\hline \multicolumn{7}{|c|}{ Saline enemas - control } \\
\hline $\begin{array}{l}\text { Basal } \\
\text { Butyrate } \\
\text { p Value }\end{array}$ & 7 & $\begin{array}{c}12.8(1.3) \\
17.5(1.3) \\
<0.05\end{array}$ & $\begin{array}{c}6.4(0.7) \\
6.9(0.6) \\
\text { NS }\end{array}$ & $\begin{array}{c}6.4(1.0) \\
10.6(1.0) \\
<0.02\end{array}$ & $\begin{array}{c}0.5(0.2) \\
0.3(0.1) \\
\text { NS }\end{array}$ & $\begin{array}{c}14(2) \\
20(5) \\
\text { NS }\end{array}$ \\
\hline \multicolumn{7}{|c|}{ Saline enemas - TNBS } \\
\hline $\begin{array}{l}\text { Basal } \\
\text { Butyrate } \\
\text { p Value }\end{array}$ & 7 & $\begin{array}{c}17 \cdot 0(1 \cdot 1) \\
17 \cdot 0(1 \cdot 4) \\
\mathrm{NS}\end{array}$ & $\begin{array}{c}7 \cdot 3(0 \cdot 7) \\
8 \cdot 6(0 \cdot 6) \\
\text { NS }\end{array}$ & $\begin{array}{c}9 \cdot 7(0.8) \\
8 \cdot 5(1.4) \\
\text { NS }\end{array}$ & $\begin{array}{l}0.8(0.2) \\
0.3(0.1) \\
<0.05\end{array}$ & $\begin{array}{c}19(2) \\
24(2) \\
\text { NS }\end{array}$ \\
\hline \multicolumn{7}{|c|}{ Butyrate enemas - control } \\
\hline $\begin{array}{l}\text { Basal } \\
\text { Butyrate } \\
\text { p Value }\end{array}$ & 6 & $\begin{array}{c}10.7(0.6) \\
15.2(0.9) \\
<0.01\end{array}$ & $\begin{array}{c}4.5(0.2) \\
5.7(0.5) \\
\text { NS }\end{array}$ & $\begin{array}{l}6.2(0.6) \\
9.5(0.8) \\
<0.01\end{array}$ & $\begin{array}{c}0.8(0 \cdot 2) \\
0.4(0.2) \\
\text { NS }\end{array}$ & $\begin{array}{c}14(3) \\
22(4) \\
\text { NS }\end{array}$ \\
\hline \multicolumn{7}{|c|}{ Butyrate enemas - TNBS } \\
\hline $\begin{array}{l}\text { Basal } \\
\text { Butyrate } \\
\text { p Value }\end{array}$ & 8 & $\begin{array}{c}17.0(0.6) \\
20.0(0.8) \\
<0.01\end{array}$ & $\begin{array}{c}7 \cdot 7(0 \cdot 6) \\
7 \cdot 8(0 \cdot 2) \\
\text { NS }\end{array}$ & $\begin{array}{c}9.3(0.7) \\
12 \cdot 2(0.8) \\
<0.02\end{array}$ & $\begin{array}{c}1 \cdot 0(0 \cdot 1) \\
0 \cdot 8(0 \cdot 1) \\
\text { NS }\end{array}$ & $\begin{array}{c}22(4) \\
28(5) \\
\text { NS }\end{array}$ \\
\hline
\end{tabular}

Values are mean (SEM) for rats on day 5 or 24 of the study in the following groups:

non-manipulated controls \pm a single saline enema on day 0 (control); TNBS enema given on day 0 (TNBS); daily saline enemas given from day 5 to 24 (saline enemas); daily butyrate enemas given from day 5 to 24 (butyrate enemas); and no daily enema therapy (untreated). The number of animals studied in each group is given. $J_{m s}, J_{s m}, J_{\text {nep }}$ and $I_{s c}$ are given in $\mu \mathrm{Eq} / \mathrm{cm}^{-2} / \mathrm{h}^{-1} ; G$ is given in millisiemens $/ \mathrm{cm}^{2}$. The p value compares the basal state with the stimulated state within each group.

activities seen at 24 days in untreated or saline enema treated rats with TNBS colitis, MPO activity in the butyrate enema treated TNBS group fell to control values by day 24 (Fig 1).

\section{$\mathrm{Na}^{+}$transport and electrical activities}

The addition of $25 \mathrm{mM}$ butyrate to the distal colons of the untreated control groups on days five and 24 of the study period stimulated $\mathrm{J}_{\mathrm{ms}}$ and $\mathrm{J}_{\text {net }} \mathrm{Na}^{+}$fluxes above basal values but did not alter $\mathrm{J}_{\mathrm{sm}} \mathrm{Na}^{+}$flux (Table II). Tissue electrical activities, $I_{s c}$ and $G$, were not changed by

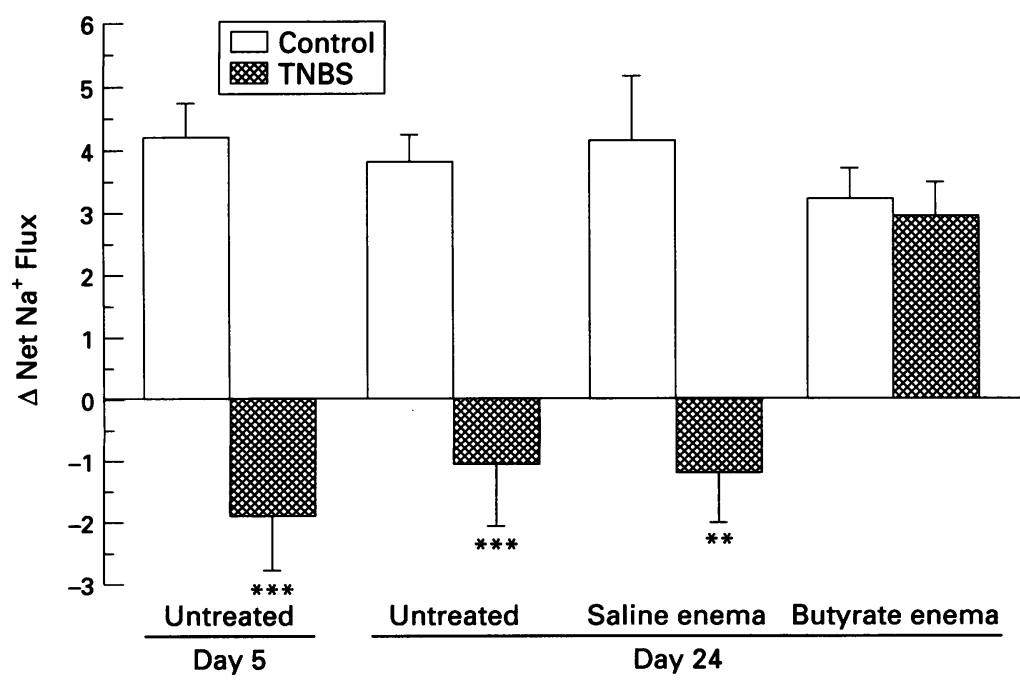

Figure 2: $\Delta \mathrm{Net} \mathrm{Na}^{+} \mathrm{Flux}=\left(\mathcal{F}_{\text {net }}\right.$ (butyrate) $-\mathcal{F}_{\text {net }}$ (basal)) in $\mu E q / \mathrm{cm}^{-2} / \mathrm{h}^{-1}$ in rat distal colon of control and TNBS groups on day five or 24 for each treatment category.

${ }_{\star \star} p<0.01, \star \star \star p<0.001$ compares the TNBS group with the respective control groups. the addition of butyrate, confirming electroneutral stimulation of $\mathrm{Na}^{+}$absorption. Similarly, in the control groups on day 24 that received either daily saline or SCFA enemas from day 5 to 23 and were not subjected to TNBS colitis, the addition of butyrate stimulated $\mathrm{J}_{\mathrm{ms}}$ and $\mathrm{J}_{\text {net }} \mathrm{Na}^{+}$fluxes above basal activities and did not change $\mathrm{J}_{\mathrm{sm}} \mathrm{Na}^{+}$flux, $\mathrm{I}_{\mathrm{sc}}$ or $\mathrm{G}$ (Table II).

In contrast, the distal colons of both the day 5 and day 24 untreated groups with TNBS colitis as well as the day 24 saline enema treated group failed to show stimulation of $\mathrm{J}_{\text {ms }}$ or $\mathrm{J}_{\text {net }} \mathrm{Na}^{+}$absorption after the addition of $25 \mathrm{mM}$ butyrate (Table II). $\mathrm{J}_{\mathrm{sm}} \mathrm{Na}^{+}$flux and $\mathrm{G}$ in these three groups and $I_{\text {sc }}$ in the day 5 and day 24 untreated TNBS colitis groups were not changed after the addition of butyrate. Also on day five, TNBS colitis caused an increase $(p<0.01)$ in $\mathrm{J}_{\mathrm{sm}} \mathrm{Na}^{+}$ flux and $G$ and a decrease $(p<0.01)$ in $\mathrm{J}_{\text {net }} \mathrm{Na}^{+}$absorption during the basal period compared with day five controls. After the addition of butyrate, $I_{s c}$ in the day 24 saline enema treated TNBS colitis group was reduced.

Unlike the other TNBS colitis groups on day 24 , distal colon of the butyrate enema treated TNBS group responded to butyrate stimulation, as evidenced by increases in $\mathrm{J}_{\mathrm{ms}}$ and $\mathrm{J}_{\text {net }}$ $\mathrm{Na}^{+}$absorption above basal values (Table II). Similar to the findings in the control groups, $\mathrm{J}_{\mathrm{sm}}$ $\mathrm{Na}^{+}$flux, Isc or $\mathrm{G}$ did not differ between the basal and stimulated periods in the butyrate enema treated TNBS group on day 24 .

An examination of $\Delta \mathrm{J}_{\text {net }} \mathrm{Na}^{+}$transport summarises these data (Fig 2). The addition of butyrate to the distal colon of all control groups stimulated $\Delta \mathrm{J}_{\text {net }} \mathrm{Na}^{+}$absorption above basal values to a similar degree (Fig 2). $\mathrm{Na}^{+}$ absorption was replaced by mild $\mathrm{Na}^{+}$secretion after the addition of butyrate to the mucosa of the day five untreated, the day 24 untreated, and the day 24 saline enema treated groups with TNBS colitis (Fig 2). In contrast in the day 24 butyrate enema treated TNBS colitis group, the addition of a physiological concentration of butyrate once against stimulated $\Delta \mathrm{J}_{\text {net }} \mathrm{Na}^{+}$absorption to values similar to those seen in all control groups not subjected to TNBS colitis.

\section{Discussion}

In these in vitro experiments, the addition of a physiological concentration of butyrate (25 $\mathrm{mM}$ ) to the mucosal side of the distal rat colon of untreated controls stimulated electroneutral $\mathrm{Na}^{+}$absorption, confirming previous findings of Binder and Mehta. ${ }^{25}$ In the rat, butyrate absorption from the lumen by distal colonic epithelial cells occurs via an apical butyrate$\mathrm{HCO}_{3}$ exchanger. ${ }^{25} 26$ Exchange of the strong base, $\mathrm{HCO}_{3}$, for the weak base, SCFA, decreases intracellular $\mathrm{pH}$, which in turn stimulates apical electroneutral $\mathrm{Na}-\mathrm{H}$ exchange. ${ }^{27}$ The apical extrusion of $\mathrm{H}^{+}$from the cell corrects intracellular $\mathrm{pH}$ and the absorption of $\mathrm{Na}^{+}$ with its subsequent basolateral transport from the cell via Na-K-ATPase stimulates colonic 
water absorption. ${ }^{25-28}$ Thus, SCFA stimulated $\mathrm{Na}^{+}$absorption plays an integral part in the colonic salvage of fluid and electrolytes.

In these experiments, untreated controls gained weight and displayed no evidence of colonic damage or inflammation. Similarly, 19 days of either saline or butyrate enema therapy given to controls did not cause colonic damage, trigger inflammation or change epithelial function. In contrast, rats subjected to a TNBS induced colonic injury developed acute weight loss and diarrhoea. Five days after TNBS administration, an extensive colonic injury was seen, as evidenced by persistent diarrhoea and pronounced inflammation. The multiple ulcers overlying a thickened mucosa and fibrous adhesions were similar to previous observations of the TNBS induced colonic injury in rats. ${ }^{20-23}$ Five days after the induction of injury, net absorption of $\mathrm{Na}^{+}$was decreased before the addition of butyrate and butyrate failed to stimulate $\mathrm{Na}^{+}$absorption. This was associated with increases in serosal to mucosal $\mathrm{Na}^{+}$flux and electrical conductance, both manifestations of increased epithelial permeability. Our findings confirm recent observations that correlated basal colonic electrolyte transport with morphological injury in this model of experimental colitis. ${ }^{23}$ Four days after injury, these investigators observed a pseudomembrane overlying an extensive area of epithelial necrosis and inflammation. This was associated with abolition of electrolyte absorption and increased tissue leakiness. During this acute phase of injury, diarrhoeal fluid losses are most probably caused by extensive epithelial damage associated with increased tissue leakiness as well as a decreased SCFA induced colonic salvage of electrolytes and fluid.

By day 24, in the untreated and saline enema treated groups with TNBS colitis, $\mathrm{Na}^{+}$ absorption in the basal period recovered to control values despite the persistence in inflammation. Addition of the SCFA butyrate, however, once again failed to stimulate the colonic salvage of $\mathrm{Na}^{+}$in these two groups. This probably contributed to persistent diarrhoeal fluid losses. Bell et al also showed a recovery of basal electrolyte transport associated with persistent inflammation and diarrhoea over this time period. ${ }^{23}$ They suggested the continued diarrhoea was caused by other mechanisms, but did not explore its pathophysiology.

The important finding of this study is the group with colitis that received butyrate enema therapy for 19 days displayed both a clinical and functional recovery. Diarrhoea ceased and weight gain recovered to control values. Colonic damage was minimal and inflammation, as measured by tissue MPO activity, decreased to the level of controls. As seen with the other TNBS groups at day $24, \mathrm{Na}^{+}$absorption in the basal period recovered to control values. Unlike the other TNBS groups, however, SCFA stimulated $\mathrm{Na}^{+}$absorption recovered in the group that received daily butyrate enema therapy. Recently D'Argenio et al showed that butyrate enema therapy promotes histological repair and reduces inflammation of TNBS induced colitis in the rat. ${ }^{22}$ This study extends D'Argenio's findings by correlating structural repair and reduced inflammation with recovery of colonic epithelial transport function. In the TNBS model of chronic colitis, these experiments show that butyrate enema therapy reduces diarrhoea by stimulating tissue repair, which results in recovery of SCFA stimulated electrolyte absorption, an important contributor to the colonic salvage of fluid and electrolytes. Similarly, in humans, enema treatment with SCFAs including butyrate has been used successfully to treat diversion colitis, refractory distal ulcerative colitis, and radiation proctitis. ${ }^{1016-1929}$ Hove et al recently showed that patients with active ulcerative colitis displayed rectal butyrate absorption equivalent to healthy controls, when provided with a pharmacological concentration $(70 \mathrm{mM})$ of butyrate. ${ }^{30}$

Butyrate enema therapy probably stimulates epithelial repair by several mechanisms. In multiple species, including the rat, butyrate serves as the primary metabolic fuel of colonocytes. ${ }^{4-615}$ In addition, butyrate induces colonic trophism by stimulating proliferation of immature epithelial cells at the base of colonic crypts. ${ }^{78}$ Interestingly, when this proliferation zone expands to involve the upper $40 \%$ of the crypt, which may be seen in response to epithelial injury, butyrate has a different role. It inhibits further proliferation and stimulates differentiation, which improves colonic function, including improved electrolyte absorption. ${ }^{1-39}$ In summary, enema therapy with the SCFA, butyrate, reduces inflammation, stimulates colonic repair, and restores colonic function in this experimental model of chronic colitis. These results support continued investigations of the role for SCFAs, especially butyrate, in the treatment of multiple types of colonic injury.

This study was supported by funds from the Crohn's and Colitis Foundation of Canada and the Medical Research Council of Canada. Dr Butzner is an Alberta Heritage Foundation for Medical Research (AHFMR) Clinica Investigator and Dr Bell is an AHFMR Clinical Fellow.

1 Fleming SE, Arce DS. Volatile fatty acids: their production absorption, utilization, and roles in human health. Clin absorption, utilization, and roles

2 Ramakrishna BA, Roediger WEW. Bacterial short chain fatty acids: their role in gastrointestinal disease. Dig Dis 1990; 8: 337-45.

3 Scheppach W. Effects of short chain fatty acids on gut morphology and function. Gut 1994; 35 (suppl 1): S35-8.

4 Bergman EN. Energy contributions of volatile fatty acids from the gastrointestinal tract in various species. Physio Rev 1989; 70: 567-90.

5 Clausen MR, Mortensen PB. Kinetic studies on the metabolism of short-chain fatty acids and glucose by isolated rat colonocytes. Gastroenterology 1994; 106: 423-32.

6 Roediger WEW. Role of anaerobic bacteria in the metabolic welfare of the colonic mucosa in man. Gut 1980; 21 : 793-8.

7 Kripke SA, Fox AD, Berman JM, Settle RG, Rombeau JL. Stimulation of intestinal mucosal growth with intracolonic infusion of short-chain fatty acids. IPEN 1989; 13: 109-16.

8 Scheppach W, Bartram P, Richter A, Richter F, Liepold H, Dusel G, et al. The effect of short-chain fatty acids on the human colonic mucosa in vitro. fPEN 1992; 16: 43-8

9 Bartram HP, Scheppach W, Schmid H, Hofmann A, Dusel $\mathrm{G}$, Richter $\mathrm{F}$, et al. Proliferation of human colonic mucosa as an intermediate biomarker of carcinogenesis: effects of butyrate, deoxycholate, calcium, ammonia and $\mathrm{pH}$ Cancer Res 1993; 53: 3283-8.

10 Harig JM, Soergel KH, Komorowski RA, Wood CM Treatment of diversion colitis with short-chain fatty acid irrigation. $N$ Engl $\mathcal{F}$ Med 1989; 320: 23-8. 
11 Butzner JD, Meddings JB, Dalal V. Inhibition of shortchain fatty acid absorption and $\mathrm{Na}^{+}$absorption during acute colitis in the rabbit. Gastroenterology 1994; 106: 1190-8.

12 Roediger WEW. The colonic epithelium in ulcerative colitis: an energy-deficiency disease? Lancet 1980; ii: $712-5$.

13 Roediger WEW, Lawson MJ, Kwok V, Grant AK, Pannall PR. Colonic bicarbonate output as a test of disease activity in ulcerative colitis. $\mathcal{F}$ Clin Pathol 1984; 37: 704-7.

14 Chapman MAS, Grahn MF, Boyle MA, Hutton M, Rogers J, Williams NS. Butyrate oxidation is impaired in the J, Williams NS. Butyrate oxidation is impaired in the Gut 1994; 35: 73-6.

15 Roediger WEW, Nance S. Metabolic induction of experimental ulcerative colitis by inhibition of fatty acid oxidation. Br F Exp Pathol 1986; 67: 773-82.

16 Breuer RI, Buto SK, Christ ML, Bean J, Vernia P, Paoluzi P, et al. Rectal irrigation with short-chain fatty acids for distal ulcerative colitis: preliminary report. Dig Dis Sci 1991; 36: 185-7.

17 Senagore AJ, MacKeigan JM, Scheider M, Ebrom JS. Short-chain fatty acid enemas: a cost-effective alternative in the treatment of nonspecific proctosigmoiditis. Dis in the treatment of nonspecific

18 Scheppach W, Summer H, Kirchner T, Paganelli GM, Bartram P, Christl S, et al. Effect of butyrate enemas on the colonic mucosa in distal ulcerative colitis Gastroenterology 1992; 103: 51-6.

19 Steinhart AH, Brzezinski A, Baker JP. Treatment of refractory ulcerative proctosigmoiditis with butyrate enemas. Am $f$ Gastroenterol 1994; 89: 179-83.

20 Morris GP, Beck PL, Herridge MS, Depew WT, Szewczuk MR, Wallace $\Pi$. Hapten-induced model of chronic inflammation and ulceration in the rat colon Gastroenterology 1989; 96: 795-803.
21 Wallace JL, Keenan CM, Gale D, Shoupe TS. Exacerbation of experimental colitis by nonsteroidal antiinflammatory drugs is not related to elevated leukotriene $\mathrm{B}_{4}$ synthesis. Gastroenterology 1992; 102: 18-27.

22 D'Argenio G, Cosenza V, Sorrentini I, De Ritis F, Gatto A Cave MD, et al. Butyrate, mesalamine, and factor XIII in experimental colitis in the rat: effects on transglutaminase activity. Gastroenterology 1994: 106: 399-404

23 Bell CJ, Gall DG, Wallace JL. Disruption of colonic electrolyte transport in experimental colitis. Am f Physiol 1995; 268: G622-30.

24 Smith JW, Castro GA. Relation of peroxidase activity in gut mucosa to inflammation. Am $\mathcal{F}$ Physiol 1978; 234: R72-9.

25 Binder HJ, Mehta P. Short-chain fatty acids stimulate active sodium and chloride absorption in vitro in the rat distal colon. Gastroenterology 1989; 96: 989-96.

26 Rajendran VM, Binder HJ. Short chain fatty acid stimulation of electroneutral $\mathrm{Na}-\mathrm{Cl}$ absorption: role of apical SCFA- $\mathrm{HCO}_{3}$ and SCFA-Cl exchanges. In: Binder $\mathrm{JH}$, Cummings J, Soergel K, eds. Falk symposium 73 short chain fatty acids. Dordrecht: Kluwer Academic, 1994: 104-16.

27 Rowe WA, Lesho MJ, Montrose $\mathrm{MH}$. Polarized $\mathrm{Na}^{+} / \mathrm{H}^{+}$ exchange function is pliable in response to transepithelial gradients of propionate. Proc Natl Acad Sci 1994; 91: gradients

28 Sellin JH. Methodological approaches to study colonic short chain fatty acid transport. In: Binder JH, Cummings J, Soergel K, eds. Falk symposium 73 short chain fatty acids. Dordrecht: Kluwer Academic, 1994: 71-82.

29 Al-Sabbagh R, Sinicrope F, Sellin J, Cleary K, Ender B, Morris M, et al. Short-chain fatty acid (SCFA) enemas for radiation colitis. Gastroenterology 1994; 106: A2.

30 Hove H, Holtug K, Jeppesen PB, Mortensen PB. Butyrate absorption and lactate secretion in ulcerative colitis. Dis Colon Rectum 1995; 38: 519-25. 